\title{
Soil, Rock, Lander...The Systems Engineering Leadership of Mars Pathfinder
}

\author{
Brian J. Sauser, Stevens Institute of Technology
}

\section{Introduction}

In the project management critical success factor literature, leadership is identified as a key factor in project success (Westerveld 2003). Within projects, project leaders who create vision and meaning, and develop fresh approaches to long-standing problems provide this leadership. System engineers are relied upon routinely to provide the engineering leadership for technical solutions in projects, but more and more, they are being relied upon to be project leaders where ideas are transferred into tangible results through a vision. They must be effective leaders, efficient managers, and technically competent, and to be successful they must take responsibility for the vision, its execution, and the ultimate business results. In complex systems projects this becomes important both technically and socially (Katz 1997). Using a famous National Aeronautics and Space Administration (NASA) project and a project leadership framework (i.e., Strategic Project Leadership ${ }^{\mathrm{TM}}$ ), this case study describes the system engineering leadership success and lessons learned of Mars Pathfinder.

\section{Strategic Project Leadership}

Strategic Project Leadership (SPL) is an approach to project management that focuses projects on creating competitive advantage and winning in the marketplace (Shenhar 2003; 2004). It is based on the realization that project management is an evolving discipline. Traditionally, projects are focused on getting the job done, operational performance, and meeting time and budget goals. SPL provides a more modern and wider view. It suggests that projects are done for business results, and that just getting the job done is not enough. The primary goal of SPL is to transform project managers and system engineers into leaders, who must deal with the strategic and business aspects of their project, and articulate a vision and a spirit, which would inspire their project teams. This leadership role is necessary in today's dynamic world, because there is no time to deal with strategy only at the executive level. The SPL framework involves a hierarchy of five componentsstrategy, spirit, organization, processes, and tools:
1. Strategy: The missing link that must be formally articulated for every project to fill in the gap between the high-level business strategy and the traditional project plan. The strategy is the project perspective, direction, and guidelines on what to do and how to do it, to achieve the highest competitive advantage and the best project results.

2. Spirit: Spirit means creating an inspiring vision, which is derived from project strategy, and building an environment of excitement and commitment that characterize all great projects. Spirit is defining and nurturing the vision that energizes and brings out the best in people. How the team is empowered to make decisions and implement them; what style management uses; and who is defined or viewed as the leadership of the organization.

3. Organization: This is how the people within the project are structured, report, collaborate, deal with difficulties, receive advice and reviews, and are trained. Who is defined as top-level management, how they are involved, how they assembled the team, how much authority they have over the project, and how they assign work.

4. Processes: This describes a project's phases and review processes, communication, project monitoring, planning, and control.

5. Tools: Tools serve to help plan, execute, and control the project. What form, means, and frequency of communication are used?

After selecting the right project strategy and creating the right spirit, project leaders deal with the more traditional components of organization, processes, and tools. The following is NASA's Mars Pathfinder described through the SPL styles of strategy, spirit, organization, processes, and tools.

\section{Case Study Approach}

Eisenhardt (1989) stated that case studies can provide description, test theory, or generate theory. She described a fundamental difference in case study research as compared 
to experimental research in the selection of the sample population. Cases are chosen for theoretical reasons, not statistical reasons. Case study research provides a conduit to go from theory to data and back to theory. In this case study the approach was to use a descriptive case study methodology where the case was defined by a descriptive theory (i.e., Strategic Project Leadership) (Yin 1994). To address any threats to validity as defined by Yin (1994) multiple sources of evidence supported by data source triangulation was used (see Table 1 for sources of data) (Denzin 1984; Stake 1995; Yin 1994), and a study protocol was established for future replication and to reduce any bias in the collection of data (Shenhar 1999). Case development and analysis was performed by the following:

1. Case Definition and Selection: Defined the case to be evaluated, and the framework in which the case was to be described.

2. Data Collection: Data collection was performed using interviews, documentation, archival and historical information, and participant observation.

3. Analysis: The analysis of the case followed an iterative process where the completion of an interview or coding of evidence was followed by an analysis to gain familiarity with the data and evaluate or reevaluate the theories.

4. Evaluation and Discussion: Once the final analysis was completed, a final iteration was performed to develop and refine a final theoretical statement about the findings.

\section{The SPL of Mars Pathfinder}

In 1993, Congress approved a plan proposed by NASA's Space Science Enterprise for faster, better, cheaper (FBC) planetary missions called the Discovery Program. To show Congress that it could be done, NASA selected two charter missions: one at the Jet Propulsion Laboratory (JPL) and one at the Johns Hopkins University Applied Physics Laboratory (APL). Mars Pathfinder was chosen at JPL as a scientific mission set out to broaden the understanding of Mars and show that FBC could be done successfully. As a product, Mars Pathfinder was a single spacecraft (lander), with microrover and several instruments designed to demonstrate a low-cost system for cruise, entry, descent, and landing on Mars. Additional objectives included the deployment and operation of various scientificinstruments: stereoscopic imager with filters on a pop-up mast, alpha proton $\mathrm{x}$-ray spectrometer (APXS), and atmospheric structure instrument and meteorology package.

With three years for development and a total cost no greater than $\$ 280$ million (including the launch vehicle and mission operations), Mars Pathfinder was to demonstrate a simple, low-cost system, at a fixed price for placing a science payload on the surface of Mars at 1/15 the cost of Viking (Viking cost $\$ 2.8$ billion in 1997 dollars). From its start, Mars Pathfinder had project constraints that were unmatched by any other NASA project and science objectives that would return an unparalleled amount of data to the largest science community associated with

Table 1. Sources of Evidence (Yin 1994)

\begin{tabular}{|c|c|}
\hline Data Type & Source \\
\hline Interviews & $\begin{array}{l}\text { Semistructured, open-ended conversational format to allow interviewees to speak freely and } \\
\text { openly about their experiences. Interviews ranged from } 30 \text { minutes to } 2 \text { hours based on the } \\
\text { interviewee's availability and depth of information. A single interview session was performed with } \\
\text { each subject, with follow-up interviews on an as-needed basis. Six key personnel related to the } \\
\text { project were interviewed. These people represented program management, project management, } \\
\text { administration, systems engineer, team member, and customer. Each interview was recorded on } \\
\text { audiotape and transcribed. }\end{array}$ \\
\hline
\end{tabular}

Documentation

Archival and Historical

Participant Observation
Formal studies, evaluations, journal articles, survey data, mass media, and physical artifacts (samples of work done).

Letters, memoranda, policy statements, regulations, proposals, guidelines, procedures, summary reports, organizational records, and personal records.

NASA gave permission for participation in its Academy of Program and Project Leadership training programs. This included project management training classes. 
a NASA mission. The philosophy of FBC was virtually unproven in NASA and would open new ways of doing business for an agency that prided itself on being on the forefront of space exploration. Mars Pathfinder would only be the beginning of what NASA would hope to be a longterm exploration of Mars and a new way of doing business. For all of Mars Pathfinder's interest and success, it was not the landing on Mars that marked its success (Viking I and II accomplished this in 1976 and 1978, respectively)-it was the means by which it was accomplished that made it unique, innovative, and electrifying.

\section{Strategy}

"Develop a plan, then improvise."

Mars Pathfinder maintained simple objectives centered on cost, schedule, and an attainment of some "modest" scientific objectives. In the end it would be the scientific community, and Congress that would judge Mars Pathfinder's success. All the management on Mars Pathfinder believed that in order to achieve the project objectives they had to be constrained. As customers to Mars Pathfinder, the scientific community would use the mountains of data to advance the scientific understanding of Mars and our solar system, support graduate students, and advance careers. For Congress, it would build faith in NASA's ability to do low-cost space science missions, and build support for future funding.

A government project is usually supported by a congressional or administrative push. In some cases they are developed from a scientific community pull. In either case there is usually little competition, but there can be a significant value, to Congress, the agency, the public, or the scientific/engineering community it supports. For Mars Pathfinder, the competitive advantage, as the rover project manager saw it, was partly skill and partly political, but once the project started there was little competitive advantage and a lot of value. For any project like Mars Pathfinder, there is a competition that exists before the project starts. What typically happens is principal investigators team up with various engineers and scientists at specific NASA centers to collaborate and write a proposal to NASA Headquarters. There may be as many as thirty other groups preparing proposals to meet the same requirements. The science instruments manager said that there is definite competition, because their will always be another center that thinks they can do it better.

The other difficulty is that while Mars Pathfinder worked toward a self-measurement of success that appeared to be straightforward, it was what Mars Pathfinder benchmarked itself against that was harder to define. As with many NASA projects post-Apollo, it is really hard for project teams to benchmark themselves against something. Rarely is there anyone to beat or is anyone doing anything even remotely similar. For Mars Pathfinder it was Viking.
Although the comparison was almost incomparable in the level of constraints, it was nonetheless compared in terms of project cost and scientific return. Most members of the Mars Pathfinder team felt that the value of Mars Pathfinder fell on the fundamental objectives and the primary customers. So ultimately they benchmarked themselves against what they promised ... deliver it on schedule, within budget, and with a level of quality data. One benchmark that can be defined is "Did we do better than last time?" This is an interesting benchmark because sometimes there is no last time and in every case you always try to do better than last time. Rarely are missions with NASA repeated identically with the expectation of achieving identical results.

The Mars Pathfinder team believed they had to have a specific and directed strategy to be successful. Simply, the strategic focus for everyone was to land a spacecraft on the surface of Mars for a budget less than, as the lander project manager put it, "the largest blockbuster movie at the time, Waterworld." The added challenge was that it had to be accomplished on a fixed cost, spacecraft plus rover, of about $\$ 200$ million and within three years. Given these programmatic constraints and the added technical challenge, the strategic focus needed to be one that could allow people to get through this really tough challenge. The rover project manager believed this was simplicity. She stated, "Modesty, simplicity were really the strategies of Mars Pathfinder." All of the managers believed in this strategy and the rover project manager emphasized it simply as, "Keep it simple stupid." But, that did not mean that the project was not challenging. The lander project manager believed the team needed a strategic focus that said, "Take risks, don't fail." That was the behavior that management stressed to the team. With a reduction in structure and policy, people were allowed to think outside the box and challenge themselves and the project. This behavior, the lander project manager believes, was critical to turning the Mars Pathfinder competitive advantage into a successful project. To create this relentless pursuit of the competitive advantage or focus, management fostered a focused vision for the project and made sure that this vision was part of everyone's approach. Mars Pathfinder team members believed in the project vision and, thus, became self-directed to achieving the strategy. There was a clear linkage between the strategy, vision, and objectives.

\section{Spirit}

"Mars Pathfinder had more spirit than any mission I've ever seen."

Due to the shear nature of the constraints placed upon Mars Pathfinder, the team felt they had to invent new ways of doing business, and that became part of the culture. A willingness to take risks, but make sure that they were able to manage those risks. As the science instruments manager stated, "The overall project had taken on a fairly 
challenging goal, so I think there was an understanding that we were willing to take some risks on this project that we might not ordinarily be taking on some missions." And by virtue of this, an atmosphere was created where people felt or were continuously reminded of the common elements of the vision. The management was conscious of the costs and schedule constraints and worked hard to make decisions that would reflect these constraints. Team members recognized this need, but were not afraid to admit and correct bad decisions. They saw management working with them and not for them. They believed that they all had to finish this project together. For example, as the lander project manager put it, "It wasn't one subsystem saying: 'Screw you. I'm going to worry about my budget.' Everybody worried about everybody else. There was a sharing. You know you talk about a really great team holding each other responsible as much as you hold yourself. And that's what we did." Each member of the Mars Pathfinder team held every other member responsible and accountable for his or her actions. They each had a deeply rooted, common commitment, purpose, and goal. They were very diverse and offered different ages and areas of expertise in science and technology. They expressed care and concern for both the individuals and the project. They had a well-balanced task-orientation, as well as people-orientation, but always remembered the super-ordinate goal of the mission.

People were more concerned with being honest and meeting the goal, than trying not to "rock the boat."Although they recognized that each individual contribution to the group effort was significant, almost without exception, they "let go" of any member who wasn't doing the job or contributing to the team effort. Every member of the team valued everyone's input, took personal ownership of their responsibilities, and understood how each member played a role in the overall success of the mission. Members of the team had mutual trust and respect for one another and had to be fully competent in his or her domain. The idea was to be hard on the issues and soft on the people. The abundance of time spent together, the relatively small number of members in the group, the challenge and constraints posed by external factors and those who did not believe in their potential success, all these forces contributed to the team's strong cohesiveness. A project engineer believed that if you get the right quality person, you can train them to do most tasks, and in an interdisciplinary environment this becomes very efficient and helpful. In addition, the collocation of much of the staff allowed for the crossing of line organizations and as one manager described, "I think the fact that everybody was there as an integrated cohesive unit as a team, doing something new, really contributed to the high-level spirit that I was able to observe on the mission. That was something very unique."

The lander project manager said that you have to have a policy (or lack of policy) that will allow you the freedom to be creative about how you do your job. He believed that is really the hallmark of being successful, and if you do not have the freedom to be creative and the constraints are really impossible, you will probably not succeed. Mars Pathfinder leadership believed in leaner staffs, minimal overhead, empowerment of the people, and a willingness to do things in new ways. From the beginning, the leadership believed in their team and believed they enjoyed work as naturally as play. They believed they were capable of selfdirection and could be motivated and responsible enough to achieve the mission's goal. The lander project manager clearly states the key factor to the success of the project was the people. They believed in being an example to the rest of the team and believed leadership begins at the top, and so does team spirit. The leadership had a clear vision, and backed up its words with actions. Management for Mars Pathfinder carried a level of respect from the team as well. Mars Pathfinder management believed that knowledge was key to empowerment. They felt that individuals became empowered to make decisions because they had access to information once available only to managers. Therefore, they made sure that individuals had access to as much information as possible.

\section{Organization}

"Build a team of different ages and experience."

Many NASA projects can become huge bureaucratic monoliths. A project engineer stated that in many NASA projects people are empowered to do their own tasks, but are not really empowered to help make strategic decisions. Mars Pathfinder tried something very novel and unique to most of NASA at the time. Mars Pathfinder management secured an entire building and they brought everybody from their line organizations into that building and relocated everybody into one location (about 200 or 300 people). They covered two floors of the building, creating a tight close-knit atmosphere where everybody was readily available. As a project engineer stated, "You just had to walk down the hall to resolve a problem and that was a very efficient way to do things." Mars Pathfinder believed in keeping the team small and, thus, keeping the organization flat. There was almost no hierarchy, and, in most areas, the group was only one deep with no one person backing up an engineer or scientist. The team was designed to be small so it could function not as a group, but as a "high performance team." They believed that a flat organization could empower the people who were doing the work. The challenge as the rover project manager put it was that “... with flat organizations you can have inexperienced people trying to do the work with no one coaching them or mentoring them."

Mars Pathfinder management believed as the lander project manager stated, "Build a team of generalist people who are not limited in scope to the confines of the work that they were trained in or are most experienced at, but 
who have the interest and ability to work beyond the limitations of their resume." They tried to put together the best technical team that they could with a combination of experience and inexperience. The rover project manager described it as, "You get the best people you can, and then you mush the organization around to fit the people." With the limitation of not being able to select from a large talent force, the lander project manager learned that it is best to work just a few people short of enough. The lander project manager believed in making people stretch by putting them in jobs they were not "qualified" for by experience, but that he felt they could handle. To support this he found strong "lieutenants," who would tell you when things were off target or just plain wrong. When selecting members for the Mars Pathfinder, team management wanted people that were going to be with the project from beginning to end. This meant being able to reduce the turnover of key technical personnel, and the ability to identify qualified staff early and foresee any organizational problems. While youth and inexperience seemed to dominate Mars Pathfinder, it maintained a level of experienced scientists and engineers to keep the project focused and directed.

In order to manage how responsibilities were allocated with Mars Pathfinder, management put the power in the team. Mars Pathfinder practiced what they called "soft projectization." It became an institutional idea where rather than having the line organization responsible for the delivery of a subsystem, they had project element managers who came out of the line organization and reported directly to the project manager. This project element manager was then responsible and accountable for their subsystem; in addition, they took complete ownership of the delivery of a particular subsystem. By empowering the project element managers with the responsibility of ownership for their subsystem, management wanted people in this position who were technically competent and could be close to the action of their subsystems. But just as the team was empowered with the responsibility to make decisions, management felt they were just as responsible for making sure the engineers and scientists got the help they needed, even if it meant taking a shift along with the engineers and scientists to make sure the work got done on schedule. Mars Pathfinder believed that commitment begins at the top. They saw top management as a champion for Mars Pathfinder and important to sustaining its success.

To perform reviews they relied a lot on outside consultants. This was something the project manager believed in and made a significant part of the budget. The project manager worked hard to make sure that the outside review board was a formal, very competent board that would work to keep the team honest. The board members consisted of technical people with recent, directly applicable, subsystem experience. These reviewers were selected based on their knowledge of what questions to ask, how to probe issues, and when an answer was satisfactory. Aside from regular training that team members had received through the course of their career, no one received any training outside of on-the-job training during the course of the project. Most everyone on the project had a four-year degree and some advanced. Few had any formal management training. Once the project started, it was rapid-paced, and there was no time for training. For some this meant some pretty quick learning, reviewing archival test results (e.g., Viking), and meeting the people who did know how to design certain systems. Therefore, the technical learning became on-the-job or real-life crash courses.

\section{Processes}

"... then test the hell out of every piece of hardware and software."

Aside from the formal design reviews (e.g., preliminary design review $[\mathrm{PDR}]$ and critical design review $[\mathrm{CDR}]$ ), Mars Pathfinder placed a lot of emphasis on informal reviews comprised of in-depth discussions of requirements and designs. Mars Pathfinder saw the formal reviews at a verification of the project status and attainment of milestones, while the informal reviews featured detailed value-added engineering analysis, problem solving, and peer review. The formal reviews were used as the gates in the development process. But, as the lander project manager stated, “They aren't crisp gates." Traditionally, the preliminary design is completed at PDR, which gives approval to go into detail design. Then, when the CDR is completed, approval is given to go into fabrication. For Mars Pathfinder this traditional approach could not work. The lander project manager stated that this not only did not work on Mars Pathfinder, but also would not work on most projects today; "There are just too many parallel threads." Therefore, the CDR becomes the point when a fair amount of the design has been completed, and hardware has already been committed in other areas. The lander project manager describes it as a "rolling wave," or a "moving target." For Mars Pathfinder the schedules drove when you needed transition and not the design reviews.

Communications were critical to moving Mars Pathfinder successfully forward in its project development. Many of the Mars Pathfinder team members attributed things like collocation, email, hallway conversations, and focused meetings to their communications success. The lander project manager placed a lot of value on face-toface communication and, thus, attempted to collocate as many of the Mars Pathfinder team members as possible. Many critical, timely decisions were made when two people crossed paths in the hall. Members did not focused on how many meetings or when they occurred but how they were conducted. Meetings were kept short (sometimes only 15 minutes), small, to the point, and offered the opportunity 
for team members to address issues or concerns. Some meetings had nothing on the agenda, but all meetings included a set of questions that were the framework for the meeting and centered on budget, schedule, and major programmatic issues and changes. Another mechanism by which communication was fostered was in the development of documentation. Mars Pathfinder made the person who generated a document (e.g. requirements, change-control processes, drawings) be the owner of it, and when there was a change needed to the document, that person had to be part of the interface to make the changes.

In some respects Mars Pathfinder followed the standard approach to resource estimation at JPL: (1) the initial budget for the project is defined by headquarters, (2) a bottom-up layout of the schedule and staffing, (3) and a bottom-up costing. For Mars Pathfinder, this quickly showed that there were not adequate reserves for the project. This triggered some major reevaluation and descoping very early in the project. Each subsystem manager had to keep track of his or her own budgets and schedules with an informal earned-value system to track performance. During the project, Mars Pathfinder believed that resources were part of the entire project and not the sole possession of any subsystem. The rover project manager stated that Mars Pathfinder believed in the sharing of resources whenever possible. One way to do this was through a barter system. This was done routinely between the rover and lander projects (e.g., mass). Mars Pathfinder did not believe in being restrained about setting up reserves. Mars Pathfinder maintenance of large reserves when it was initially started was recognized as critical to solving problems. Therefore, when problems were identified the team tried to assess the cost impact and then a change-control board did the allocation of reserves to those problems, with first-level managers sitting on this board. To maintain the budget, when the science experiments/instruments were selected they were cost-capped. This meant that they were unable to spend any more money than they proposed to accomplish the task. Every team member of Mars Pathfinder will say that the key to reducing the technological and requirements uncertainty was to freeze design early and test. Rather than do extensive trade-off studies and analyses, Mars Pathfinder moved rapidly from prototyping to the engineering model stage. The lander project manager felt that testing was even part of the vision and culture. He explained, "We were going to test this thing very aggressively, end to end, as many times as we could, testing every aspect of it because it's a single-string machine. You know one failure in one part or one component could take out the whole mission. And everybody knew that." Mars Pathfinder team members put in twice as many hours testing the spacecraft as anybody thought was needed. Mars Pathfinder dealt with challenges that not all planetary missions encounter, landing on Mars. Most space missions are designed to come within close proximity of a planet or celestial body, but landing is very hard.

The Mars Pathfinder team believed they had a reasonably strong system engineering effort. To ensure this people were devoted to working across subsystems. The lander project manager believed that every one of his project element managers was a systems engineer and a very tight team. Because the project management had a system engineering mindset, people were not afraid to be a systems engineer or think like a systems engineer. The team believed that having people work "cradle to grave" also reduced the uncertainty. Management also believed that by allowing people to all phases of the projects development addressed many of the issues associated with integration.

Not only was a high level of risk inherent in the project because of the technological challenges, but also on the way the project was to be managed. Mars Pathfinder built things early and then tested them. Team members had the system integrated and going into test with 40 percent of their resources still left. When they found things they were able to fix them. As the rover project manager explained, "Other missions like Cassini do systems engineering on the front end with a lot of requirements and create a big paper trail. Most of our decisions were made by rapid prototyping. As you put something together you test it; it either works or it doesn't, and then you write your documents based on the testing."

\section{Tools}

"... nobody has time to read them."

Mars Pathfinder management felt that documenting the development of Mars Pathfinder was critical to be able to empower the team. Although documentation was an obligation of the contract, the rover project manager felt that documentation is only a representation of reality, as much as you can make it, and performance specs are largely just predictive. Therefore, the ability to capture knowledge and manage it was only as good as you made it. A project library was used as a tool to ensure that knowledge was documented and. A hard-copy library was maintained with all critical documents (e.g., engineering drawings, test reports). These documents were kept lean. For example, the Level 3 requirements document for the flight systems was only about a half-inch thick, compared to the Level 3 requirements document for Galileo or Cassini that are volumes thick. A librarian maintained this library. Another big portion of the knowledge for Mars Pathfinder was managed by the knowledge of individuals. It was the responsibility of the team to be the keepers and sharers of the knowledge.

Mars Pathfinder management felt that lessons learned and the capturing of lessons learned were a valuable tool for project success. The Mars Pathfinder team believed in lessons learned from start to finish. For example, with 
Mars Pathfinder and Mars Global Surveyor (MGS), after the failure of Mars Observer (the precursor to MGS), Mars Pathfinder decided that they were not going to overload the science, thus, maintained a modest science mission to ensure mission success. For Mars Pathfinder, seasoned engineers and scientists were used to learn from past projects. The value in getting lessons learned from people is as the rover project manager stated, “... nobody has time to read them, specially on a FBC project. The only way to use lessons learned is to have the people that learned them or to go through the documentation. The way it is documented now, it is almost impossible."

During the project, the team captured lessons learned as they went through the project. For example, after the launch, the project team had a lessons learned activity that produced a two-inch thick summary of the lessons learned at subsystem and system level. At the end of the mission, a second lessons learned document was created. This document has since been passed on to other projects. Also, during the cruise period, team management prepared a comprehensive summary of the lessons learned. They emphasized the importance of innovative management techniques, concurrent engineering/teaming practices, and spacecraft architecture. To relay these lessons learned, senior project staff hosted information transfer seminars on Mars Pathfinder lessons learned for all of JPL. The difficulty with lessons learned as a project engineer stated is that it is a "pull system." You have to pull them from the people and the documents. The rover project manager stated that another problem with lessons learned at NASA is that learning is about one project long.

\section{Summary}

\section{Lessons Learned from Mars Pathfinder}

To be successful the Mars Pathfinder team had to do business differently from traditional and standard operating procedures. They worked to develop a unique culture centered around leaner staff, reduced overhead, empowered team members, a willingness to do things in new ways, and a management team that believed in a team of capable, selfdirected members. To build this cultural rules were lifted, and authoritative structures were minimized. The team was hand-picked with many being experts in their field, but most of all these people had to have the ability to be generalist and multidisciplined. These types of people were picked from a skill set of different ages and experiences, but all brought with them a level of energy and creativity to carry the project from beginning to end. The leadership was committed to the goal and all actions were in line with the goals of launching every day. This meant having a clear vision and making sure that the vision was part of every action. Mars Pathfinder was successful at being on time, on budget, and on target, and management valued the people that they empowered every day.

\section{Mars Pathfinder Success Defined by the Systems Engineering Leaders}

Mars Pathfinder was described by SPL in retrospect, so even without the SPL analysis the Mars Pathfinder team had defined their reasons for project leadership success. Below is a list of specific events and actions that the Mars Pathfinder systems engineering leadership identified during interviews as strategic factors of success:

- Reduced Requirements: Many requirements were pushed back to drive cost and reduce risk. Management felt that this could not be accomplished without a "capabilities-driven" project. They believed the capabilities of the people, hardware, designs, and architecture would drive the project to success.

- Hands-off Top Management: In order to give Mars Pathfinder management the ability to push back requirements and allow people to think differently, they believed top management had to stay handsoff. Giving the team the freedom to do what they felt needed to be done, even if it meant breaking the rules.

- Getting People to Think Differently: Mars Pathfinder was unlike any project that anyone on the project team had worked on before. Mars Pathfinder management said that breaking the traditional mindset of how projects were done was an ongoing challenge.

- Managing Risk: Risk was seen as a distracter to maintaining focus. When time is critical, there can be no time for stopping to adjust for unplanned risk. To manage risk management attempted to understand risk early and develop a mitigation strategy; avoided risk with qualified parts, materials (COTS where needed), and process; and performed rigorous testing and rapid prototyping.

- High Reliance on the People: By removing much of the structure, Mars Pathfinder believed the people became the foundation of the project and, thus, critical to its success; therefore, this meant a foundation built on people's knowledge, communications skills, and commitment.

- Parallel Processes with More Peer Reviews: Reviews from technically qualified and experienced peers was seen as one of the most significant factors in contributing to the Mars Pathfinder's success and maintaining focus.

- Co-location: Mars Pathfinder felt this allowed management to express the strategic focus on a constant basis in real-time.

- End-to-End Design: People worked the project from beginning to end. Mars Pathfinder believed this kept people focused on the success of the project because they knew they would be there in the end; success or failure. 


\section{References}

Denzin, N. 1984. The research act. Englewood Cliffs, NJ: Prentice Hall.

Eisenhardt, K.M. 1989. "Building theories from case study research.” Academy of Management Review, 14, no. 4, $532-50$.

Katz, R. 1997. The human side of managing technological innovation. New York: Oxford Press.

Shenhar, A.J. 1999. Real life project analysis-Guidelines. Hoboken, NJ: Stevens Institute of Technology.

Shenhar, A.J. 2003. Strategic project leadership: Focusing Projects on Business Results. Paper presented at the PMI Global Congress, Hague, Netherlands.

Shenhar, A.J. 2004. "Strategic project leadership: Toward a strategic approach to project management." $R \ll D$ Management.

Stake, R. 1995. The art of case research. Newbury, CA: Sage Publications.

Westerveld, E. 2003. "The project excellence model: Linking success criteria and critical success factors." International Journal of Project Management, 21, 411-18.

Yin, R.K. 1994. Case study research: Design and methods. Thousand Oaks, CA Sage Publications.

\section{Biography}

Brian J. Sauser holds a B.S. from Texas A\&M University in Agriculture Development with an emphasis in Horticulture Technology, a M.S. from Rutgers University in Bioresource Engineering, and a Ph.D. from Stevens Institute of Technology in Technology Management. $\mathrm{He}$ has worked in government, industry, and academia for more than 10 years as both a researcher/engineer and director of programs. He has managed an applied research and development laboratory in life sciences and engineering at NASA Johnson Space Center, was Program Director of the New Jersey - NASA Specialized Center of Research and Training, where he managed a multiinstitutional, multi-disciplinary science and engineering research center working to generate new knowledge and technology for life support systems, and was a Project Specialist with ASRC Aerospace responsible for managing technology utilization and assessment, and commercial partnership development at NASA Kennedy Space Center. $\mathrm{He}$ is currently a Research Assistant Professor at Stevens Institute of Technology in the Systems Engineering and Engineering Management Department. 